\title{
An Ontological Sketch for Robust Non-Reductive Realists
}

\author{
Bruno Niederbacher ${ }^{1}$
}

Published online: 25 November 2016

(c) The Author(s) 2016. This article is published with open access at Springerlink.com

\begin{abstract}
The aim of this article is to draw a sketch of an ontology for Realist Non-Naturalist Cognitivists. A distinction is made between moral property-universals and moral property-particulars. It is argued, first, that moral property-universals have the same ontological status as non-moral property-universals; second, that moral property-universals have many instances in the spatio-temporal world; third that these moral property-instances or -particulars have the same ontological status as non-moral property-particulars.
\end{abstract}

Keywords Moral property - Moral laws · Ontological status · Parfit's non-metaphysical cognitivism - Light moral ontology

We evaluate actions morally. We make such utterances as

1. "It is morally good of Fred to host the refugee Hasan" or

2. "It is morally good of anyone to help those in need."

As a Metaethical Cognitivist, I interpret many such moral utterances as moral assertions by which we express our belief in certain moral propositions. With sentence (1) we express our belief in a proposition with a particular moral content, namely that Fred's hosting the refugee Hasan is morally good; with sentence (2) we express our belief in a proposition with a general moral content, namely that it is morally good of anyone to help those in need. Let us assume that both propositions are true. As

Bruno Niederbacher

Bruno.Niederbacher@uibk.ac.at

1 Department of Christian Philosophy, University of Innsbruck, Karl-Rahner-Platz 1, 6020 Innsbruck, Austria advocate of a realist conception of truth, for non-moral propositions as well as for moral propositions, I ask: What could the moral reality be like that makes such propositions true? Which kinds of entities would it involve? My aim in this article is, first, to propose a moral ontological sketch for robust non-reductive realists, second, to give a few arguments that speak for it, and third, to contest some arguments which endorse the view that moral properties are ontologically lighter than non-moral properties.

\section{A Moral Ontological Sketch}

The moral ontology I am proposing contains several kinds of entities: First, I assume that there are action-particulars, for example, Fred's hosting the refugee Hasan at time $t$. Second, I assume that there are property-particulars, the bearers of which are action-particulars. Some of them are non-moral property-particulars such as being happinesscontributing, some are moral property-particulars such as being morally good. ${ }^{1}$ Third, I assume that there are actionuniversals, or kinds of action, for example, the actionuniversal of hosting refugees or of helping the needy. Fourth, I assume that there are property-universals which can again be divided into non-moral property-universals and moral property-universals. ${ }^{2}$

\footnotetext{
${ }^{1}$ I use "moral property" in a comprehensive sense for deontic and axiological properties.

${ }^{2}$ Universals are here conceived as ontologically posterior to particulars and as abstractions from particulars. I do not think that universals exist without being at least instantiated once. In contrast to other views on universals, this account does not conceive of universals as being capable of multiple location at the same time. See Lowe $(2010,245)$.
} 
Fig. 1 Moral ontological square action-universals are characterized by

property-universals

are instantiated by<smiles>C=CC</smiles>

action-particulars are characterized by

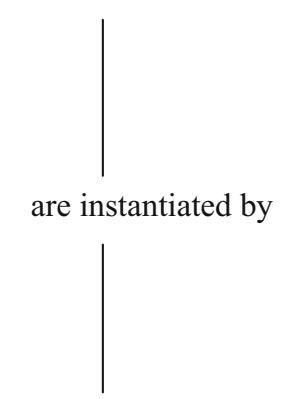

property-particulars
These are the four kinds of entities I will address in this article, but, of course, they do not exhaust the kinds of entities that are needed in a comprehensive ontology. Such an ontology would also contain substances, relations, events, both as universals and as particulars, etc. Some readers might wonder why I have not included habits (dispositions to react and to act). Habits are also said to be morally good or bad. Hence one might think that I ought also to assume habit-universals and habit-particulars. However, in my view, habits are properties of persons. A good habit, such as the virtue of temperance, is a dispositional property of a person: it disposes him/her to act in a certain way. Such a property can itself be a bearer of a moral property. Therefore, to account for moral habits, it is sufficient to assume property-universals and property-particulars, and higher-order property-universals and propertyparticulars.

Next, the relationships between the four kinds of entities I am assuming have to be explored. I will do this with the help of Fig. 1, which utilizes Jonathan Lowe's ontological square (see Lowe 2006, 22). However, it has to be said immediately that Lowe would not countenance the kinds of entities I assume here. ${ }^{3}$

The relationships to be explored are instantiation and characterization. First, the relationship between actionuniversals and action-particulars is that of instantiation. An action-particular is an instance of an action-universal. Fred's hosting the refugee Hasan is an instance of the action-universal hosting refugees. In the same way is the relationship between property-universals and propertyparticulars one of instantiation. A property-particular is an instance of a property-universal. The particular happinessconduciveness of Fred's hosting Hasan is an instance of the property-universal of being happiness-conducive, and the particular moral goodness of Fred's hosting Hasan is an instance of the property-universal of being morally good.

\footnotetext{
3 Lowe's ontological square contains as fundamental kinds of entities: substantial universals, individual substances, property universals and property instances.
}

Second, the relationship between action-universals and property-universals is one of characterization. The actionuniversal of helping those in need is characterized by the non-moral property-universal of being happiness-conducive and by the moral property-universal of being morally good. In the same way, the relationship between an action-particular and property-particulars is one of characterization. Fred's action of helping Hasan in his need is characterized by the particular happiness-conduciveness and by the particular goodness.

A question that needs to be addressed is what types of relationship instantiation and characterization are. One might think that we denote, with the expressions "instantiation" and "characterization", relational property-universals or relational property-particulars, but this is not so. Here they are conceived to be only formal predicates that do not denote additional kinds of entities (Lowe 2006, 44-49). One could argue for this in the following way. Fred's hosting the refugee Hasan necessarily instantiates its action-universal of hosting refugees. It is part of the essence of Fred's hosting the refugee Hasan that it is an instance of the action-universal of hosting refugees. In the same way, Fred's action's being morally good necessarily instantiates its moral property-universal of being morally good. It is part of the essence of this action's moral goodness that it is an instance of the property-universal of being morally good. Similarly, one can say, regarding characterization, that it is part of the essence of Fred's action's being morally good that it characterizes Fred's action, because this particular moral goodness depends for its very identity on its being Fred's action's moral goodness.

Another reason for holding the view that "characterization" denotes no additional entity is motivated by trying to avoid Bradley's regress (Bradley 1893). For example, if a particular goodness of an action-particular were connected by a relation-particular (an instance of the characterization-relation), then two more relation-particulars would be needed: one to connect the action-particular to the first relation-particular, another one to connect the first 
relation-particular to goodness, and so on. Bradley's regress threatens also if one understands the characterization that holds between action-universals and their essential properties as itself a relational property-universal. However, I understand characterization of an action-universal by a property-universal in this way: it belongs to the essence of an action-universal to have a certain essential characteristic. It belongs to the essence of the action-universal of helping the needy to be morally good or morally obligatory. Helping the needy would not be what it is if it were not morally good or obligatory.

What is not yet clear from the Fig. 1 is the relation that holds between certain non-moral properties and moral properties of actions, considered as particulars as well as universals. I propose that the relationship is one of grounding. I illustrate this relationship with the help of Fig. 2.

The moral property-particular of an action-particular is grounded in some non-moral property-particulars of this action. The moral property-particular of Fred's action's being morally good is grounded in some non-moral property-particulars of his action, such as the property-particular of his action's bringing about more happiness in the world than would have been otherwise. There is a sense in which grounding is stronger than supervenience. The idea is not just that a moral property-particular is instantiated iff some non-moral property-particulars are instantiated, or that there cannot be a difference in moral property-particulars without there being a difference in non-moral property-particulars. Rather, grounding could be stated as follows: The property-particular $b$ of an action-particular $e$ is grounded in property-particular $a$ iff $a$ makes it the case that $e$ has $b$; or iff $e$ 's being $a$ makes $e$ 's being $b$ the case. ${ }^{4}$ Moreover, at the level of the universals, the relationship is parallel: Moral property-universals are grounded in nonmoral property-universals. The property-universal of being morally good is grounded in some non-moral propertyuniversals of the action-universal of helping the needy, for example in the property-universal of being happinessconducive. Grounding is here, like instantiation and characterization, regarded as a purely formal relationship, not a relational property-universal.

\section{Some Reasons for Holding a Rich Non-Reductive Moral Ontology}

So far I have sketched the basic elements and formal relationships of a moral ontology which can be labeled as "Rich Non-Reductive Moral Ontology". However, some

\footnotetext{
4 The relation of grounding is developed in Correia and Schnieder (2012).
}

might object that this ontology is far too rich. They could claim that one can easily think of positions which are also non-reductive, but much more economical. A first position could hold that we need to assume nothing more than action-particulars plus non-moral and moral property-universals. A second position could maintain that we need merely assume action-particulars plus non-moral and moral property-particulars. In what follows I will examine these two positions. For reasons of space I will confine the discussion to moral properties and leave aside the discussion of the ontology of actions.

\subsection{There are Moral Property-Universals but No Moral Property-Particulars}

Some might claim that moral predicates denote moral property-universals, and that it suffices to assume their existence-there is no need to posit moral property-particulars. I will consider two possible arguments for this claim.

The first argument might proceed from the thesis that all properties are universals (see Armstrong 1997). A property-universal such as greenness is instantiated by a particular chair. The particular instance of the universal is this particular chair itself. There is no need to assume in addition a particular greenness that characterizes this particular chair. Since all properties are universals, moral properties are universals too. In response, there is an argument in favor of assuming properties-particulars that starts with perceptions (see Lowe 2006, 23-24). Our perceptions seem to be of this greenness of this chair, this roughness of this surface, this taste of this roast beef. Now, perception involves a causal relation between perceiver and perceived, but in order to participate in causal relationships, the entities in question must be particulars. We might also think of other properties of things. It is this particular shape of a shoe that causes the particular imprint in the soil. It is this particular weight of the man that causes the depth of the imprint. These must be property-particulars of things since they enter causal relationships. It is the particular way that these things are which explains the form and depth of the imprint in the soil. Thus, we have a good reason to believe in the existence of property-particulars in general.

We have also good reason to believe in the existence of non-moral property-particulars of action-particulars. Fred's action of hosting Hasan has the property of making Hasan happier. It can be argued that this property is a propertyparticular of Fred's action, since it can also enter causal relationships. The particular way the action is explains, for example, Hasan's new attitude and behavior. Now, if the non-moral properties of Fred's action are property-particulars, it is also reasonable to assume that the moral property of Fred's action is a property-particular as well, since 
Fig. 2 The grounding relationship

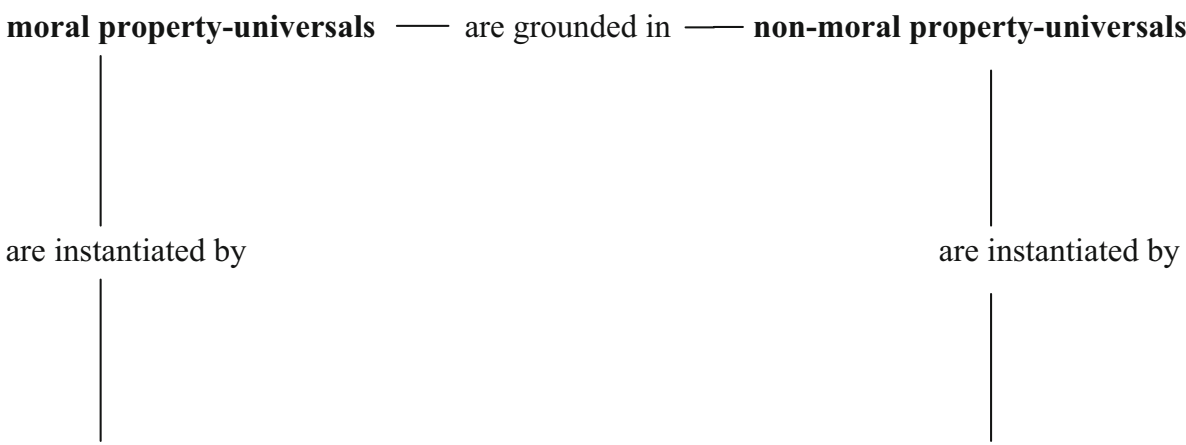

moral property particulars — are grounded in — non-moral property-particulars it is grounded in some of the non-moral property-particulars of the action. ${ }^{5}$

A second argument for assuming that moral properties are universals might run as follows: Compare the properties of being morally good or bad, right or wrong (and so forth) with the property of being a valid proof. ${ }^{6}$ Suppose that a series of symbols written on a piece of paper presents a valid proof. We might say that these symbols on the page are particulars and exist in the spatio-temporal world. However, their property of being a valid proof is not a property-particular but rather a property-universal. Applied to metaethics, then, one might say: Action-particulars are part of the spatio-temporal world. However their property of being morally good or bad is not a property-particular but rather a property-universal. For example, Napoleon's action of invading Russia is an event (or rather series of events) in the spatio-temporal world, that is, a particular entity. ${ }^{7}$ The non-moral properties of this action, such as bringing about immense suffering, are also property-particulars of this action. These non-moral properties make it the case that Napoleon's action has the moral property of being wrong. However, this moral property of his action is not a property-particular but rather a property-universal. Thus, there are non-moral property-particulars but no moral property-particulars. Moral properties are all property-universals.

In my view, however, the comparison is flawed. Napoleon's action is a particular (or a series of particulars), an event or series of events in the spatio-temporal world. And the symbols written on the paper are also particular entities in the spatio-temporal world. However, these symbols represent a valid proof. Thus, the symbols written on some page do not have the property of being a valid proof but

\footnotetext{
5 Whether moral properties can participate in causal relations is a highly controversial question which I dare not enter here. See: Harman (1977), Sturgeon (1988), Leiter (2001), Sturgeon (2006a, b).

6 The comparison is taken from Parfit $(2011,486)$. However, I do not intend here to analyze Parfit's comparison in the context of his argument.

${ }^{7}$ I take this example from Parfit $(2011,486)$.
}

rather the property of representing a valid proof. On the other hand, Napoleon's action itself has the property of being wrong. I see the case as follows: If Napoleon's action is a particular entity, and if the wrong-making non-moral properties of this action of bringing about immense human suffering are also property-particulars, then it is reasonable to assume that the moral property of being wrong is also a property-particular of this action. Take another normative property: a belief's property of being justified. Let's assume that a version of reliabilism is true. A belief is a particular state of a person. Let us say, further, that this belief was produced in a reliable way. Thus, this belief has the property of being produced in a reliable way which is a property-particular. This property-particular confers on the belief the property of being justified-in my view, the justifiedness of this belief is a different property-particular of this particular belief.

If one accepts moral property-particulars, the question for the truthmaker of propositions with a particular moral content is easy to answer. The proposition Fred's action of hosting the refugee Hasan is morally good is made true by Fred's action's having the property-particular of being morally good.

\subsection{There are Moral Property-Particulars but No Moral Property-Universals}

One might ask: If you assume that there are moral property-particulars, why do you assume that there are also moral property-universals? You should assume entities only if there is a good reason to. In my view, the assumption that there are moral property-universals is justified for a reason similar to that which justifies the additional assumption of non-moral property-universals. Some ontologists justify the assumption of property-universals because they help us to understand natural laws (for example: Armstrong 1992; Lowe 2006). Similarly, I would justify the assumption of action-universals and propertyuniversals on the grounds that they help us understand moral laws. 
I draw here on ideas presented by Jonathan Lowe. According to Lowe, such nomological statements as "Benzene is flammable", "Common salt dissolves in water" or "Electrons have unit negative charge" express laws of nature. The form of such laws is: "[...] substantial kind $K$ is characterized by $F$-ness, or, even more simply, $K$ is $F$." (Lowe 2006, 132) What we have here are two kinds of universals: substance-universals and propertyuniversals. The substance-universal is characterized by the property-universal, or, in other words, the substance-universal possesses the property-universal. This is how they are tied together. A law-statement like "Benzene is flammable" denotes a state of affairs consisting in the kind benzene possessing the property-universal of being flammable. The obtaining of this state of affairs makes the statement "Benzene is flammable" true (Lowe 2006, 127).

This account of natural laws has several advantages. First, if we interpret natural laws as universal generalizations, we are unable to distinguish between law-like and accidental generalizations. Furthermore, we would have to say that laws of nature hold because similar particulars behave in similar ways. However, we would not be in a position to explain the regularities. The regularities could be mere coincidences. In contrast, if we account for laws of nature by assuming substance-universals and propertyuniversals, then we can explain the regularities. Particular quantities of benzene possess the disposition or liability of burning because they are instances of the substance-universal benzene whose nature is to be flammable (Lowe 2006, 131). This account differs from Armstrong's account of laws of nature. According to Armstrong, laws of nature consist, in their simplest form, in two property-universals linked to each other by the second-order property-universal of necessitation. The form of a law is, accordingly, "F-ness necessitates G-ness" (Armstrong 1983). This account also offers an explanation for the non-accidental regularity that obtains between particulars. However, one difficulty of this view is whether it can account for exceptions. If F-ness necessitates G-ness, then every particular that exemplifies F-ness must also exemplify G-ness-but this is not the case.

Here lies the second advantage of Lowe's account of laws of nature: according to it, laws of nature admit exceptions. One can clarify this by the following consideration. We make such assertions as "This benzene burns". By this we can either mean that this benzene is disposed to burn or that this benzene is actually burning. In the first case, we are talking about a disposition, in the second about an occurrence. To say that an object has the disposition to $F$ is to say that it instantiates a kind which is characterized by a property-universal of being $F$-which is just the law $K$ is $F$. To say that an object is occurrently $F$ is to say that an object is characterized by the property-particular $F$-ness which is an instance of the property-universal of being $F$. A law of nature explains the dispositions of an object. However, the law does not determine the object's actual behavior. That this benzene has the power to burn does not imply that it always burns. According to Lowe's view, laws of nature "determine tendencies amongst the particulars to which they apply, not their actual behavior, which is a resultant of many complex interactions implicating a multiplicity of laws". (Lowe 2006, 29) With a law-statement we express how an object is disposed to behave. Such a statement is not falsified if an object does not actually behave this way.

I suggest applying this account to moral laws. Accordingly, general substantive moral statements such as "Helping those in need is morally required", "Promises ought to be kept", "Killing the innocent is wrong" express moral laws. ${ }^{8}$ The form of such laws is: action-kind $A$ is characterized by the property of being $M$, where $M$ stands for a moral property. This account involves two kinds of universals: action-universals and moral property-universals. They are linked by the action-universal being characterized by the moral property-universal. A statement like "Helping those in need is morally required" denotes a state of affairs consisting of the action-universal of helping those in need, which possesses the property-universal of being morally required. It is this moral law itself which makes the moral law-statement true.

Now, it is clear that action-universals are neither natural kinds nor substance kinds, the entities described by natural laws. However, a parallel construction can nevertheless be maintained. I consider actions as belonging to the category of events. If actions are events, then a moral law will involve an event-universal and a property-universal. "Killing the innocent is wrong" would, then, denote a state of affairs consisting of the event-universal of innocent killing which is characterized by the property-universal of being morally wrong. ${ }^{9}$

\footnotetext{
${ }_{8} \mathrm{I}$ assume that there are fundamental and less fundamental moral laws. But, for reasons of space, I cannot deal here with the question of how they are ordered and related to each other.

${ }^{9}$ Short comparisons with two similar views are apt at this point. The first is Marc Murphy's view of moral laws (Murphy 2011, 30-44). He utilizes the Armstrong/Dretske/Tooley account of natural laws and assumes that a moral law consists in a relation between two universals. For example, the moral law that one should refrain from killing innocent persons is analyzed in the following way: Being a killing of an innocent person morally necessitates being refrained from. The property-universal of being a killing of an innocent person is related to the property-universal of being refrained from by the second-order property of being morally necessitating. Murphy claims that he can account for the fact that moral laws exhibit defeasibility: "to say that defeasibly, being A morally necessitates being performed means that in privileged conditions, being A selects being performed, and so in those privileged conditions the corresponding moral necessity holds" (Murphy 2011, 41-42). According to my account,
} 
This account of moral laws has advantages over some other accounts. First, if we were to account for moral laws in terms of universal generalizations, then we would be unable to distinguish law-like generalizations from accidental ones. ${ }^{10}$

Second, we would have to say that a moral law holds because similar action-particulars have similar moral properties. The moral law that killing the innocent is wrong would hold because all instances of killing innocent people were characterized by the property-particular of being wrong. However, this does not seem to be the right direction of explanation. In contrast, if we account for moral laws in terms of action-universals which are characterized by moral property-universals, then we can explain the regularity, and the direction of explanation would go the other way-which seems more intuitive: this killing of the innocent has the tendency of being wrong because according to a moral law it belongs to the essence of the action-universal killing of the innocent to be characterized by the property-universal of being morally wrong. Fred's hosting of the refugee Hasan has the tendency of being morally obligatory because it belongs to the essence of the action-universal of hosting refugees to be characterized be the property-universal of being morally obligatory.

A third advantage of this view of moral laws is that it can account for exceptions. It is a notorious problem for all who assume the existence of several moral laws that these laws exhibit defeasibility. Action-particulars are always embedded in circumstances, and the moral value of an

\section{Footnote 9 continued}

however, the moral law consists rather in the fact that the actionuniversal killing of an innocent person is characterized by the property of being wrong. The property of being wrong is not thought to be a relational property, although it is a property that ontologically depends on actions and their non-moral properties. A second account which takes moral properties also to be relational properties is suggested by Aaron Elliott. In his attempt to find a metaphysical explanation of the supervenience between natural and moral properties on the general as well as on the specific level, he says that "moral properties are specific relations between moral principles and acttypes with certain natural properties" (Elliott 2014, 650). What he seems to assume is that action-types, which are probably considered to be universals, and moral principles (whose ontological status is not made clear) are related to each other by a moral property. He says that it is the "content of the principle forbidding certain act-types, that grounds the relational property", and later that "wrongness is just being prohibited by a moral principle". The similarity between Elliott's account and mine is that I also assume action-types which I consider to be action-universals that feature in moral principles or moral laws. However, I think that the property of being prohibited is also a moral property. Thus, I see no need to assume additional moral properties that relate the principles to the action-types. In my view, an action-type has the moral property-universal of being right/wrong. And this is just what a moral law consists in.

${ }^{10}$ Murphy (2011, 18-21) elaborates some more problems with the view that moral laws are universal generalisations. action-particular also depends on the circumstances. We saw that, according to Lowe, laws of nature determine tendencies amongst the particulars to which they apply rather than determining their actual behavior. Their actual behavior results from "many complex interactions implicating a multiplicity of laws" (Lowe 2006, 23). Similarly, laws of morality do not determine the actual moral value of action-particulars, because action-particulars are embedded in complex circumstances involving a multiplicity of moral laws. We assume, for example, that breaking a promise is morally wrong. Nevertheless, there might be circumstances in which breaking a promise, because of the involvement of several moral laws in these circumstances, is the right course of action. The account of moral laws proposed here allows the following suggestion: An action-particular instantiates an action-universal which is characterized by a moral-property-universal. In virtue of being an instance of this action-universal, the action-particular has the tendency of, say, being wrong. That it has this tendency to be wrong, does not always imply that it is actually wrong. Whether or not it is actually wrong, that is, whether it has the propertyparticular of being wrong, depends on which other moral laws are involved in the circumstances.

Two traditions in the history of philosophy corroborate this view. First, according to the scholastic tradition, an action-particular's being morally good or bad is determined not only by the action-universal it might instantiate, but also by all of the relevant circumstances in which it might come about, such as: the actor's intention, the action's consequences, the means by which it is performed, ways of doing something, the place and tie in which the action is performed, the person who performs it, and so forth. ${ }^{11}$ Thomas Aquinas gives an illuminating hint concerning why the circumstances in which an action-particular is embedded can affect whether it falls under one species of good and evil rather than another. The explanation is that the circumstance is itself related to a different moral norm. ${ }^{12}$ The moral value of an action-particular is the result of the many circumstances in which the action is performed

\footnotetext{
${ }^{11}$ See for example Thomas Aquinas, Summa Theologiae I-II, 18, 4: "Accordingly a fourfold goodness may be considered in a human action. First, that which, as an action, it derives from its genus; because as much as it has of action and being so much has it of goodness, as stated above. Secondly, it has goodness according to its species; which is derived from its suitable object. Thirdly, it has goodness from its circumstances, in respect, as it were, of its accidents. Fourthly, it has goodness from its end, to which it is compared as to the cause of its goodness."

12 Thomas Aquinas, Summa Theologiae I-II, 18, 10: "And in this way, whenever a circumstance respects a special order of reason, either for or against, the circumstance must give to the moral action the species, whether good or bad.".
} 
and in which a variety of moral norms may apply. ${ }^{13}$ Second, William D. Ross distinguishes between prima facie duty and actual duty. He writes: "We have to distinguish from the characteristic of being our duty that of tending to be our duty. Any act that we do contains various elements in virtue of which it falls under various categories. In virtue of being the breaking of a promise, for instance, it tends to be wrong; in virtue of being an instance of relieving distress it tends to be right. Tendency to be one's duty may be called a parti-resultant attribute, i.e. one which belongs to an act of some single component in its nature. Being one's duty is a toti-resultant attribute, one which belongs to an act in virtue of its whole nature and of nothing less than this" (Ross 1930, 28). Moral laws determine tendencies of being good, bad, or obligatory among the action-particulars to which they apply. But the moral property-particulars which action-particulars actually have is a result of many circumstances involving many different moral laws.

\section{Moral Properties Have a Similar Ontological Status as Non-Moral Properties}

With a sketch of a moral ontology and some reasons for favoring it on the table, I will finally discuss the sense in which these moral entities can be said to exist; or, to put the question differently, what the ontological status of moral entities is. By "moral entities" I mean moral properties and moral facts. According to what one might call Light Moral Ontology (LMO), there are moral properties and moral facts but they have no ontological status. Derek Parfit has recently proposed such a view, which he calls "Non-Metaphysical Cognitivism". In what follows I will examine his position. I will argue that there are no good reasons for holding LMO.

\subsection{Parfit's Non-Metaphysical Cognitivism}

Parfit writes: "(1) There are some claims that are irreducibly normative in the reason-involving sense, and are in the strongest sense true. (2) But these truths have no ontological implications. (3) For such claims to be true, these reason-involving properties need not exist either as natural properties in the spatio-temporal world, or in some non-spatio-temporal part of reality." (Parfit 2011, 486)

Sentence (1) states a version of metaethical cognitivism according to which (1.1) some normative assertions-for example, "It was wrong for Napoleon to invade Russia"-

\footnotetext{
13 One should distinguish the ontological question from the epistemological one. I am dealing here with the ontological question only, and not with the question of how human beings acquire knowledge or justified belief concerning which law among several moral laws applies in certain circumstances.
}

are claims and thus have a truth-value; (1.2) these claims are analytically irreducible to non-normative claims; and (1.3) some of these claims are in the strongest sense true. Sentence (2) states that these true normative claims have no ontological implications. A first exploration of what could by meant by "no ontological implications" is given in sentence (3): Although Parfit thinks that "there are" normative properties and normative facts, he believes neither that these entities are identical with natural entities which exist in the spatio-temporal world nor that they exist in some non-spatio-temporal part of reality. So in what sense do these entities exist?

Parfit argues against ontological actualism (i.e. the view that all that exists exists actually) and the view that "to exist" must always be used in the same single, actualist sense. He distinguishes different senses of "there is" or "to exist": first, a wide, general sense in which there are concrete entities in the spatio-temporal world like the Earth; but also possible entities like possible persons, events, and actions which might never actually exist; and finally abstract entities like propositions, meanings, numbers, and duties. In addition to existing in this wide sense, some of these entities, such as the Earth, also exist in a further, narrow actualist, sense. What about my possible visit to Aunt Lisbeth? This exists in the wide sense, but not in the narrow actualist sense. Besides existing in the wide sense, there is also a possibilist sense of "existence" in which my possible visit exists. Furthermore, my duty to visit Aunt Lisbeth exists in the wide sense, but also in a "distinctive, non-ontological sense" (Parfit 2011, 480, 2011, 481, 2011, 719). While my possible visit to Aunt Lisbeth has lesser ontological status than my actual visit, my duty to visit her has no ontological status at all. Parfit writes: "Like numbers and logical truths, these normative properties and truths have no ontological status" (Parfit 2011, 487), and later, when speaking about necessary truths, he says: "[...] these truths are not about metaphysical reality, since they do not imply that certain things exist in some ontological sense." (Parfit 2011, 747) Thus, Parfit distinguishes between truths which are about "metaphysical reality" and truths which are not about metaphysical reality. Normative truths are of the latter sort. Although we do not invent them but rather discover them, such truths have no ontological implications.

Before assessing this claim, it will be useful to clarify what Parfit intends to convey by the expressions "truth" and "distinctive non-ontological sense of existence".

With "a normative truth" one could mean

1. a true normative proposition, or

2. a normative fact (or: an obtaining normative state of affairs) 
Parfit seems to use the word "normative truth" in sense (1) when he speaks of "ontological implications" or "claims". In this case, a normative truth would be a true normative proposition. But Parfit also speaks frequently about normative facts and argues that they are irreducible to non-normative facts. (Parfit 2011, 324) How does he conceive of the relationship between (1) and (2)? He clearly does not think that normative facts make true normative propositions true. For he writes of necessary truths in general and thus also of necessary normative truths, "[...] these necessary truths are not made to be true by there being some part of reality to which these truths correspond." (Parfit 2011, 747) Presumably, he thinks that true normative propositions are identical with normative facts. This interpretation is also suggested by a non-moral example given by Parfit. He writes,

(O) It might have been true that nothing ever existed: no living beings, no stars, no atoms, not even space or time.

Some might object that $(\mathrm{O})$ could not have been true, for if nothing ever existed, then there would be the truth that nothing existed, and this would be self-contradictory. Parfit thinks that the objection fails because $(\mathrm{O})$ "is a claim about all the kinds of entities that might exist in an ontological sense [...] But truths themselves do not have to exist in such a sense. Truths need only be true." (Parfit 2011, 482) Parfit's remark here makes it plausible to suppose that with "true normative propositions" he means the same as with "normative facts".

Now to the second clarification, the clarification of the expression "distinctive non-ontological sense of existence". Parfit distinguishes many senses of "existence". Here is a list, though probably not an exhaustive one, of these senses:

1. the one wide sense, which I'll call "existence ${ }_{1}$ ";

2. the narrow actualist sense (i.e., entities that exist as concrete parts of the spatio-temporal world), which I'll call "existence 2 ";

3. the possibilist sense, which I'll call "existence,";

4. the distinctive non-ontological sense, which I'll call "existence 4 ".

My question concerns "existence 4 ". What does the distinctive non-ontological sense of "exist" consist in? Parfit gives us only negative characterizations: it is neither the narrow actualist nor the possibilist sense. Going from semantics to ontology, he speaks of entities which have "no ontological status", and of truths which are "not about metaphysical reality" (Parfit 2011, 481, 2011, 747), and again: "These properties and truths are not, in relevant senses, either actual or merely possible, or either real or unreal." (Parfit 2011, 478) So far I have presented an outline of Parfit's position. But what are his reasons for holding this stance which I call Light Moral Ontology (LMO)? In what follows I will reconstruct three possible reasons for holding LMO: an epistemological reason, a semantic reason and an ontological reason.

\subsection{Some Reasons for Endorsing Light Moral Ontology (LMO)}

(1) A first reason might be epistemological. The question is: How do we go about discovering whether a claim is true? If "we must answer some questions about what exists, in an ontological sense", then claims do have ontological implications (Parfit 2011, 479). However, if we don't need to answer this question, then claims need not have any ontological implications. Take mathematical claims such as that there are prime numbers greater than 100. In order to find out whether such a claim is true, we "don't need to answer the question whether numbers really exist in an ontological sense, though not in space and time." (Parfit 2011, 479-480).

This is how Parfit reasons, but this reason is disputable. It is right that we proceed differently in order to solve different questions in different areas. However, whether this epistemological observation suffices to make the ontological divide is dubious. We do not have to ask whether numbers exist in an ontological but not spatiotemporal sense when we try to discover whether there are prime numbers greater than 100 , but this implies only that, in order to answer questions about certain entities, we do not need to ask after the sense in which these entities exist. However, this does not imply that these entities have no ontological status. Applied to morality: There are questions in morality which can be answered without having to ask whether moral properties exist or in what sense they exist. In order to find out whether I ought to visit my Aunt Lisbeth, I do not need to ask whether the property of being obligatory exists and in what sense it exists. However, this is no reason to suppose that we could not also ask these questions and that this duty could not exist also in some ontological sense of "exists".

(2) A second reason for endorsing LMO might be semantic. Concerning necessary truths in general, Parfit writes: "And since these truths are necessary, they do not have to be made true by some part of reality to which they correspond. This dependence goes the other way. It is reality that must correspond to these truths." (Parfit 2011, 749) Since he believes that (some) normative truths are necessary, then on his view these truths do not have to be made true by some part of reality to which they correspond.

I have three comments to make on this remark. First: Do necessary truths have no truthmakers? I would maintain that they do have truthmakers. Usually, necessary truths are 
divided into the analytic and the synthetic. In order to make progress here, we ought to distinguish:

1. true sentences

2. true propositions

3. facts as truthmakers.

Let us first look at analytic sentences. Analytic sentences are said to be true "in virtue" of the meanings of the words in the sentence. "Green is a color" is an example of an analytic sentence. To be a color is part of the meaning of the word "green". Going from words to concepts, we might say: The concept of being a color belongs to the concept of being green. Now, do analytic sentences have truthmakers? One possible answer would be: Yes, the sentence "Green is a color", or the proposition that green is a color, is made true by the fact that the concept being $a$ color belongs to the concept being green; in other words, by the fact that the conceptual implications obtain. ${ }^{14} \mathrm{My}$ preferred answer, however, carries a larger ontological commitment: The proposition that green is a color is made true by the fact that the property-universal of being green has the higher-order property-universal of being a color. What does it mean, then, that analytic sentences are true "in virtue" of the meanings of the words in the sentence? I would say, in this context, that the expression "in virtue" does not indicate that the meanings of the words are the truthmakers of the sentence but rather that the truth of the sentence is already implied by the meanings of the words.

Synthetic sentences can also be necessarily true. Claims of scientific identity like "Heat is molecular kinetic energy" are examples of such sentences. "Heat is molecular kinetic energy" expresses the proposition that heat is molecular kinetic energy. This proposition is true. Does it have a truthmaker? A possible answer would be: The proposition is made true by the fact that it is molecular kinetic energy that can make objects have all the properties which are denoted by the complex concept of heat, for example, the property of turning solids into liquids, of turning liquids into gases, or of causing us to have certain sensations. ${ }^{15}$

Parfit assumes both analytic and substantial (i.e., nonanalytic) normative propositions. His example of an analytic normative sentence is: "If some man was punished for some crime that he is known not to have committed, this man's punishment could not be just" (Parfit 2011, 490). One could say: Being unjust belongs to the concept punishing innocent people. According to my view, what makes

\footnotetext{
14 Armstrong $(2012,70)$, voices this idea when he says: “[...] the truthmakers for analytic truths are the meanings of the words or symbols in which these truths are expressed."

${ }^{15}$ I am using Parfit's analysis of scientific identity claims; see Parfit $(2011,335)$
}

the proposition true is a moral law which consists of the action-universal of punishing the innocent having the moral property-universal of being unjust.

Parfit's example of a substantial normative sentence that is not analytic is: "We have reasons to prevent or relieve the suffering of any conscious being, if we can" (Parfit 2011, 747). In my view, the truthmaker for this non-analytic sentence is the moral law consisting in the actionuniversal of preventing or relieving the suffering of any conscious being having the moral property-universal of being right.

My second remark is this: Not all true moral propositions are true necessarily. There are also contingently true moral propositions. Whenever we claim that a particular action is morally good, bad, obligatory, and so forth, such a claim would, if it were true, not necessarily be true. I suppose that the proposition that in invading Russia Napoleon acted wrongly is a contingently true moral proposition. If necessarily true moral propositions needed no truthmakers because they were necessarily true, what about contingent moral propositions? Wouldn't they still need truthmakers?

One might be inclined to respond that contingent moral propositions are derived from combining necessary moral propositions with contingent non-moral ones, such as:

1. It is morally wrong to bring about immense suffering.

2. In invading Russia, Napoleon brought about immense suffering.

3. It was morally wrong for Napoleon to invade Russia.

Proposition (3) is a contingent moral proposition which is derived from the necessary moral proposition (1) and the contingent non-moral proposition (2), and therefore the search for a truthmaker for contingently true moral propositions is misguided-so the objection goes.

Now, it is true to say that contingent moral propositions are derived from necessary moral propositions. However, this is a logical or epistemological claim which does not make the search for a truthmaker for (3) misguided. I can make the point with a non-moral example. The proposition Napoleon is mortal is derivable from the propositions All humans are mortal plus Napoleon is a human. From this, it does not follow that the proposition Napoleon is mortal does not have a truthmaker. It is Napoleon's mortality that makes the proposition that Napoleon is mortal true. Similarly, from the fact that a contingent moral proposition is derived from a necessary moral proposition plus a contingent non-moral proposition, it does not follow that the contingent moral proposition does not have a truthmaker.

My third remark concerns Parfit's claim that, since these truths are necessary, "they do not have to be made true by some part of reality to which they correspond. This dependence goes the other way. It is reality that must correspond to 
these truths" (Parfit 2011,749). What he seems to mean is the following: True moral propositions are not of the kind which must fit the world. It is the other way round. It is the world that ought to fit the moral propositions. I would say: Of course, we want reality to correspond to true moral propositions in the sense that people act in ways that fulfill the requirements set out in those propositions. However, this does not mean that there couldn't also be a moral reality to which true moral propositions correspond. Parfit's claim seems to presuppose that "metaphysical reality" is restricted to actual, space-time reality. But why should we accept this presupposition?

(3) A third consideration for endorsing LMO might be ontological. Parfit holds that predicates express concepts many of which refer to properties (Parfit 2011, 264). He also believes in the existence of properties which no particular thing has, such as the property of being the first man to walk on the Sun (Parfit 2011, 264). This claim suggests that he assumes properties to be universals some of which are and some of which are not exemplified by particular things. Parfit does not explicitly deal with the ontology of properties. I presume, however, that he believes in property-universals, and would say that they exist not only in the wide sense but also in the distinctive non-ontological sense of "exist". Hence property-universals generally would plausibly enjoy "existence ${ }_{1}$ " and "existence ${ }_{4}$ ", but not "existence 2 ".

If I am right in reconstructing Parfit's view, I would have three remarks to make. First, he seems to assume properties which are not instantiated, like the property of being the first man to walk on the Sun. I would doubt that such properties exist at all. I only assume the existence of property-universals which have instances. ${ }^{16}$ Moral property-universals have millions and millions of instances and are thus ontologically not on a pair with a "property" like being the first man to walk on the Sun.

Second, let us compare moral property-universals with non-moral property-universals which do have instances. I see no reason to deny moral-property-universals the ontological status which non-moral-property-universals are said to enjoy. I agree with Parfit that such property-universals do not exist as spatio-temporal entities in the world. However, I would not draw the conclusion that they have no ontological status.

Third, it is not clear to me whether Parfit believes in the existence of property-particulars. I gave some reason for believing that they exist. If the particular greenness of a particular chair exists, it would be an entity in space and time. It would be reasonable to suppose that this greenness of this particular chair has not only "existence ${ }_{1}$ " but also "existence ${ }_{2}$ ". The same point applies in the moral case:

\footnotetext{
$\overline{16}$ See footnote 1.
}

Napoleon's action of invading Russia is an event in space and time. This event exemplifies non-moral properties, such as bringing about immense suffering. These properties are property-particulars of this action and thus also entities in space and time. In virtue of these non-moral properties, the action exemplifies the moral property of being wrong, again a particular property of this action. It would be reasonable to suppose that this particular wrongness of this particular action has not only "existence ${ }_{1}$ " but also "existence 2 ".

\section{Conclusion}

This was an attempt to draw a sketch of a rich non-reductive moral ontology: its basic elements and the relationships between them. This ontology accounts for truthmaking of general moral statements like "Helping those in need is morally good/required" as well as of particular moral statements like "Fred's hosting the refugee Hasan is morally good". A general moral statement is made true by a moral law consisting of an action-universal which is characterized by a moral property-universal. A particular moral statement is made true by the action-particular's being characterized by the moral property-particular. Moreover, I have tried to argue that there is no reason to deny moral properties ontological status. Since I distinguish between property-universals and property-particulars, I would maintain, first, that moral propertyuniversals have the same ontological status as non-moral property-universals; second, that moral property-universals have millions and millions of instances, that they are exemplified by countless actions and characters of persons in this spatio-temporal world. Third, I maintain that these moral property-instances or -particulars have the same ontological status as non-moral property-particulars. Thus in my view there is no ontological difference (in terms of ontological status) between non-moral property-universals and moral property-universals, and between non-moral property-particulars and moral property-particulars.

Acknowledgments Open access funding provided by University of Innsbruck and Medical University of Innsbruck.

Open Access This article is distributed under the terms of the Creative Commons Attribution 4.0 International License (http://creative commons.org/licenses/by/4.0/), which permits unrestricted use, distribution, and reproduction in any medium, provided you give appropriate credit to the original author(s) and the source, provide a link to the Creative Commons license, and indicate if changes were made.

\section{References}

Armstrong D (1983) What is a law of nature?. Cambridge University Press, Cambridge 
Armstrong D (1992) Properties. In: Mulligan K (ed) Language, truth and ontology. Kluwer, Dordrecht, pp 14-27

Armstrong D (1997) A world of states of affairs. Cambridge University Press, Cambridge

Armstrong D (2012) A sketch for a systematic metaphysics. Oxford University Press, Oxford

Bradley FH (1893) Appearance and reality. Swan Sonnenschein, London

Correia F, Schnieder B (eds) (2012) Metaphysical grounding. Understanding the structure of reality. Cambridge University Press, New York

Elliott A (2014) Can moral principles explain supervenience? Res Philos. 91(4):629-659

Harman G (1977) The nature of morality. Oxford University Press, Oxford

Leiter B (2001) Moral facts and best explanations. Soc Philos Policy 18:79-101

Lowe EJ (2006) The four-category ontology. A metaphysical foundation for natural science. Oxford University Press, Oxford
Lowe EJ (2010) A neo-aristotelian substance ontology: neither relational nor constituent. In: Tahko TE (ed) Contemporary aristotelian metaphysics. Cambridge University Press, Cambridge, pp 229-248

Murphy MC (2011) God and moral law. On the theistic explanation of morality. Oxford University Press, Oxford

Parfit D (2011) On what matters, vol II. Oxford University Press, Oxford

Ross WD (1930) The right and the good. Clarendon, Oxford

Sturgeon N (1988) Moral explanations. In: Sayre-McCord G (ed) Essays on moral realism. Cornell University Press, Ithaca, pp 229-255

Sturgeon N (2006a) Moral explanations defended. In: Dreier J (ed) Contemporary debates in moral theory. Blackwell Publishing, Malden, pp 241-262

Sturgeon N (2006b) Ethical naturalism. In: Copp D (ed) The oxford handbook of ethical theory. Oxford University Press, Oxford, pp 91-121 